\title{
Limitation of High Pitch Sound Perception in Nontumor Patients with Auditory Brainstem Implantation
}

\author{
Hyun Seung Choi ${ }^{1}$, Jae Young Choi ${ }^{2}$, In Seok Moon ${ }^{2}$, Mi Ran $\mathrm{Bae}^{2}$, \\ Bo Gyung Kim ${ }^{3}$, Minbum Kim${ }^{4}$, Jin Woo Chang ${ }^{5}$, and Junhui Jeong ${ }^{1}$ \\ ${ }^{I}$ Department of Otorhinolaryngology, National Health Insurance Service Ilsan Hospital, Goyang; and \\ ${ }^{2}$ Department of Otorhinolaryngology, Yonsei University College of Medicine, Seoul; and \\ ${ }^{3}$ Department of Otorhinolaryngology-Head and Neck Surgery, Soonchunhyang University College of Medicine, Bucheon; and \\ ${ }^{4}$ Department of Otorhinolaryngology-Head and Neck Surgery, Catholic Kwandong University College of Medicine, Incheon; and \\ ${ }^{5}$ Department of Neurosurgery, Yonsei University College of Medicine, Seoul, Korea
}

\section{비종양 환자의 청성뇌간이식술에서의 고음역 인지의 한계}

최현승 ${ }^{1} \cdot$ 최재영 ${ }^{2} \cdot$ 문인석 $^{2} \cdot$ 배미란 $^{2} \cdot$ 김보경 $^{3} \cdot$ 김민범 $^{4} \cdot$ 장진우 $^{5} \cdot$ 정준희 $^{1}$

국민건강보험 일산병원 이비인후과, ${ }^{1}$ 연세대학교 의과대학 이비인후과학교실, ${ }^{2}$ 순천향대학교 의과대학 이비인후과학교실, ${ }^{3}$

가톨릭관동대학교 의과대학 이비인후과학교실, ${ }^{4}$ 연세대학교 의과대학 신경외과학교실 ${ }^{5}$

\footnotetext{
Received May 15, 2017

Revised July 6, 2017

Accepted July 18, 2017

Address for correspondence

Junhui Jeong, MD, PhD

Department of Otorhinolaryngology,

National Health Insurance Service

Ilsan Hospital,

100 Ilsan-ro, Ilsandong-gu,

Goyang 10444, Korea

Tel $+82-31-900-0983$

Fax $+82-31-900-0343$

E-mail jeongj@nhimc.or.kr
}

Background and Objectives Auditory brainstem implantation (ABI) is another option for hearing rehabilitation in non-neurofibromatosis type 2 patients who cannot undergo cochlear implantation (CI). However, the average performance of ABI is worse than that of CI. We analyzed the psycho-electrical parameters of each electrode and psycho-acoustic response to different frequency sounds in nontumor patients with ABI.

Subjects and Method Sixteen patients with ABI from July 2008 to May 2013 were included in the study. They were followed up for 4 to 56 months. Among them, 12 were prelingual deaf with a narrow internal auditory canal or cochlear ossification. The remaining four were postlingual deaf adults with severely ossified cochleae. We analyzed the electrical parameters [impedance, threshold level ( $\mathrm{T}$ level), and dynamic range] of each of the 12 electrodes. We also evaluated the sound field pure-tone threshold, Ling 6 sound detection-identification test (Ling 6 test), and pitch ranking data of these patients.

Results The impedance, $\mathrm{T}$ level, and dynamic range did not significantly differ among electrodes. However, the pure-tone threshold to sound field stimulation was elevated in the high tone area, where more variables were found than in the low frequency area. Patients could not identify /S/ and /Sh/ sounds in the Ling 6 test. The mean T level and the dynamic range of the three highest pitch-perceiving electrodes in each patient was higher and narrower, respectively, than those of the three lowest pitch-perceiving electrodes.

Conclusion The nontumor patients with ABI have difficulty perceiving high pitch sound. More sophisticated penetrating type electrodes and, if possible, bimodal stimulation with CI, could be considered. Korean J Otorhinolaryngol-Head Neck Surg 2018;61(5):235-41

Key Words Auditory brainstem implantation · Cochlear ossification Narrow internal auditory canal $\cdot$ Nontumor $\cdot$ Outcomes.

This is an Open Access article distributed under the terms of the Creative Commons Attribution Non-Commercial License (http://creativecommons.org/licenses/by-nc/4.0) which permits unrestricted non-commercial use, distribution, and reproduction in any medium, provided the original work is properly cited. 


\section{Introduction}

Auditory brainstem implantation (ABI) was originally developed for the hearing rehabilitation of patients with neurofibromatosis type 2 (NF-2). ${ }^{1)}$ Although ABI can generate auditory sensations in most patients with NF-2, the performance thereof is much worse than that for cochlear implantation (CI) in this group of patients. ${ }^{2,3)}$ Moreover, only a limited number of patients $(0-21 \%)$ reported the ability to understand speech in the auditory alone mode after $\mathrm{ABI} .^{4-7)}$

First reported by Colletti, et al. ${ }^{8)}$ the performance of nontumor patients who have undergone $\mathrm{ABI}$ is much better than that in NF-2 patients. Accordingly, ABI has been utilized as another option for hearing rehabilitation and speech development in patients who have contraindications to CI, such as cochlear nerve deficiency and severe cochlear ossification. ${ }^{9-13)}$ According to data from Verona University, ${ }^{13)}$ the average openset sentence recognition score without visual cue was $63 \%$ in the nontumor group, which was much better than that in the NF-2 group. Sennaroglu, et al. ${ }^{12)}$ also reported that all children with inner ear anomaly responded to ABI, and most of them discriminated pitch in the auditory only mode. Other reports ${ }^{9-11)}$ also showed much better auditory performance after ABI in nontumor deafness than that in NF-2 patients. Nonetheless, the average performance of $\mathrm{ABI}$ is still not as good as that for $\mathrm{CI}$ and largely varies across patients. ${ }^{14)}$

The cochlear nucleus, the target site for ABI, has quite different characteristics from the spiral ganglion. The cochlear nucleus is composed of various types of cells including inhibitory neuron, and anatomical and physiological information regarding tonotopy is very limited. ${ }^{15)}$ As a sequence, the ability to perceive pitch and pitch-placing patterns widely varies in patients who have undergone ABI. Moreover, no good surgical landmark for stimulation of cochlear nucleus exists. For these reasons, the average performance of nontumor patients with $\mathrm{ABI}$ is usually worse than those with CI. Nevertheless, most long-term data regarding the performance with $\mathrm{ABI}$ came from NF-2 patients. Thus, the performance of nontumor patients which can be quite different from NF-2 patients need to be evaluated more intensively in terms of frequency-specific hearing levels and pitch perception.

We analyzed the psycho-electrical parameters of each electrode and the psycho-acoustic response to different frequency sounds in nontumor patients who received ABI.

\section{Subjects and Method}

\section{$A B I$ and processor fitting}

Sixteen subjects who received ABI from July 2008 to April 2013 were included in the present study. The Pulsar CI100 ABI device (Med-El Co., Innsbruck, Austria) was implanted via a suboccipital approach $(n=15)$ or a translabyrinthine approach $(n=1)$ with the collaboration of neurosurgeons. Eight to ten weeks after the ABI surgery, the speech processor was activated. Further adjustments and evaluation of performance were scheduled every third month. Patients whose speech processor was activated started speech rehabilitation therapy once or twice a week. This study received Institutional Review Board approval (IRB No. 1-2010-0019).

\section{Surgical procedure}

ABI device was implanted via suboccipital approach with the collaboration of the Departments of Otorhinolaryngology and Neurosurgery. First, craniotomy was performed in the suboccipital area, and then a dural incision was made to expose and retract the cerebellum so that the cochleovestibular nerve, facical nerve, and lower cranial nerves were observed, as well as the flocculus of the cerebellum. Further retraction of the cerebellum along the glossopharyngeal nerve allowed identification of the choroidal plexus. Either removal or retraction of the choroidal plexus led to visualization of cerebrospinal fluid gushing from the foramen of Luschka and identification of the lateral recess of the fourth ventricle. The electrode array was inserted into the lateral recess. ${ }^{9)}$

All the patients underwent surgery by one surgeon except the first patient, who had been operated by Dr. Colletti. Intraoperative electrically evoked auditory brainstem response (eABR) showed good responses in all patients and postoperative three-dimensional reconstruction computed tomography confirmed the correct positioning of the electrode array into the lateral recess. Based on these the electrode arrays were expected to be inserted into the exact area with equivalent depth.

\section{Processor fitting and programming}

The patients were fitted with an ABI 8 to 10 weeks after the surgery. The activation or initial fitting of the speech processor was performed in an intensive care unit under the monitoring of pulse rate, blood pressure, and respiratory rate. Refitting and adjustments were scheduled three times during the first 3 months and then every 3 months after initial stimulation. ${ }^{9}$ 


\section{Assessment of auditory performance}

A battery of tests was used to evaluate auditory performance after ABI. The overall improvement in auditory performance was assessed by category of auditory performance (CAP) scores. In addition, Infant Toddler Meaningful Auditory Integration Scale (IT-MAIS) and Meaningful Use of Speech Scale (MUSS) scores were obtained in prelingually deaf children. Closed-set measures were evaluated using Ling 6 sound detection-identification test (Ling 6 test) and word identification and sentence recognition tests in Korean. One- and twosyllable word identification tests and Daily Sentences in Korean test were used to evaluate open-set speech perception after receiving $\mathrm{ABI}{ }^{9)}$

\section{Ling 6 test and sound field pure-tone audiometry (PTA)}

The ability to detect and discriminate six sound phonemes (/Ah/, /Oo/, /Ee/, /m/, /Sh/, and /s/) was evaluated in an auditory only, open-set format which included low-, mid-, and highfrequency components of speech. ${ }^{16)}$ The test was performed at a 3-feet distance without visual cues. Sound field audiometric testing was performed with ABI. Sound field stimuli comprised five identical $300-\mathrm{msec}, 10-\mathrm{msec}$ rise/fall, pure-tone bursts (in sine phase), with 300-msec silent periods between bursts, delivered from a speaker located approximately $45^{\circ}$ to the aided side of the patient $1.0 \mathrm{~m}$ away.

\section{Pitch ranking}

To determine the appropriate tonotopic order of the electrodes, we performed pitch ranking during the initial ABI activation. Briefly, two selected electrodes are stimulated in succession at a comfortable level (C level), and the patient is asked to compare which stimulation is higher in pitch. When the ordering of 12 electrodes is completed, the correct tonotopic position of electrodes is checked again by sweeping all the electrodes.

\section{Statistical analysis}

Data are summarized using the mean and standard deviation. Statistical analysis was performed using SPSS for Windows version 16.0 (SPSS Inc., Chicago, IL, USA). A $p$-value less than 0.05 was considered statistically significant in oneway analysis of variance or Bonferroni-corrected independent t-tests.

Table 1. Demographic data of patients with congenital deafness

\begin{tabular}{|c|c|c|c|c|c|}
\hline Patient no. & Age* $(\mathrm{Y}: M)$ & Cause of deafness & Combined disease & Cl history (site)/benefit & $F / U(M)$ \\
\hline 1 & $1: 6$ & CND & Facial nerve palsy & - & 56 \\
\hline 2 & $5: 10$ & CND & CHARGE, blindness, MR & $+(\mathrm{I}) /-$ & 30 \\
\hline 3 & $18: 11$ & CND & - & $+(1) /-$ & 32 \\
\hline 4 & $2: 10$ & CND & Facial nerve palsy & $+(\mathrm{C}) /+$ & 47 \\
\hline 5 & $9: 4$ & CND & - & $+(I) /-$ & 7 \\
\hline 6 & $6: 1$ & CND & Sacral deformity & $+(\mathrm{I}) /-$ & 41 \\
\hline 7 & $2: 5$ & CND & - & - & 31 \\
\hline 8 & $7: 5$ & CND & CHARGE, MR & $+/(\mathrm{I}) /-$ & 25 \\
\hline 9 & $9: 4$ & CND & Hemophilia & $+/(1) /-$ & 25 \\
\hline 10 & $2: 11$ & CND & CHARGE, blindness, MR & $+/(1) /-$ & 9 \\
\hline 11 & $21: 11$ & CND & - & - & 4 \\
\hline 12 & $20: 6$ & Meningitis & - & - & 13 \\
\hline
\end{tabular}

*age at auditory brainstem implantation. Y: year, $\mathrm{M}$ : month, Cl: cochlear implantation, F/U: follow-up period after auditory brainstem implantation, CND: cochlear nerve deficiency, CHARGE: Coloboma of the eye, Heart defects, Atresia of the nasal choanae, Retardation of growth and/or development, Genital and/or urinary abnormalities, Ear abnormalities and deafness syndrome, MR: mental retardation, I: ipsilateral to auditory brainstem implantation, C: contralateral to auditory brainstem implantation

Table 2. Demographic data of patients with postligual deafness

\begin{tabular}{cclccc}
\hline Patient no. & Age* $(\mathrm{Y})$ & \multicolumn{1}{c}{ Causes of deafness } & Age at deafness $(\mathrm{Y})$ & Deaf duration $(\mathrm{Y})$ & $\mathrm{F} / \mathrm{U}(\mathrm{M})$ \\
\hline 13 & 49 & Chronic otitis media (B) & 12 & 37 & 51 \\
14 & 51 & Meningitis & 9 & 42 & 12 \\
15 & 56 & Chronic otitis media (L), Vestibular schwannoma (R) & 53 & 3 & 46 \\
16 & 52 & Chronic otitis media (B) & 9 & 43 \\
\hline
\end{tabular}

*age at auditory brainstem implantation. $Y$ : year, F/U: follow-up period after auditory brainstem implantation, M: month, B: both, L: left, R: right 


\section{Results}

\section{Subjects and overall performance with $A B I$}

Twelve of the 16 patients were prelingual deaf patients with a narrow internal auditory canal or cochlear ossification after meningitis (Table 1); meanwhile, the remaining 4 patients had postlingual deafness due to cochlear ossification after meningitis or chronic otitis media (Table 2). The age of the subjects at the time of implantation ranged from 1.5 to 56 years. Twelve of 16 patients experienced previous CI. We followed up the patients for 4 to 56 months (mean of 28 months) after activation of ABI. Except for one patient (\#13) who discontinued using the ABI device due to non-auditory stimulation, the remaining 15 patients used the $\mathrm{ABI}$ device daily. In most patients, auditory performance gradually improved over time. Three patients used the ABI device in the bimodal mode with contralateral $\mathrm{CI}(\mathrm{n}=2)$ or a hearing aid $(\mathrm{n}=1)$.

Among 12 patients with congenital deafness, 2 patients understood the sentences under the open-set condition without a visual cue (CAP score $\geq 5$ ). Aided by lip reading, four patients were able to understand the sentences after ABI (CAP scores 3 and 4). The remaining 6 patients with additional handicaps, such as mental retardation or blindness, only responded to environmental or speech sounds (CAP scores 1 and 2). Among all patients, four were categorized with postlingual deafness due to an ossified cochlear. Two of them understood the sentences under the open-set condition without a visual cue (CAP $\geq 5$ ). One patient utilized the ABI with lip reading (CAP 4). One patient who was deaf for a long period of time discontinued the use of the ABI device due to a tingling sensation on the upper arm. The early results of these patients have been previously reported.'

\section{Psycho-electrical parameters of each electrode}

We compared the impedance of each electrode in 16 patients. As shown in Fig. 1A, the impedance ranged from $5.8 \pm 2.5$ to $6.8 \pm 3.5 \mathrm{kOhm}$ in each electrode. No significant difference was noted between the deep and superficial electrodes. In four electrodes (Nos. 4, 5, 9, and 11), high impedance was detected from four patients, and the No. 12 electrode could not be activated in two patients due to high impedance. We also compared the threshold level ( $\mathrm{T}$ level) for 11 patients in whom the behavior or subjective response to electrical stimulation was reliable. The $\mathrm{T}$ level varied from $117 \pm 44$ current units to $209 \pm 69$ current units in each electrode, but there were no significant differences among the electrodes (Fig. 1B). In two patients, deeply inserted electrodes (Nos. 1, 2, and 3) could not be used due to non-auditory stimulation. In eight patients who could describe stimulation intensity, we also compared the dynamic range of each electrode. This range was found to be between $401 \pm 189$ current units and $520 \pm 194$ current units, a finding that was similar among all the electrodes (Fig. 1C).

\section{Psychoacoustic parameters}

The PTA threshold in sound field aided by ABI was checked
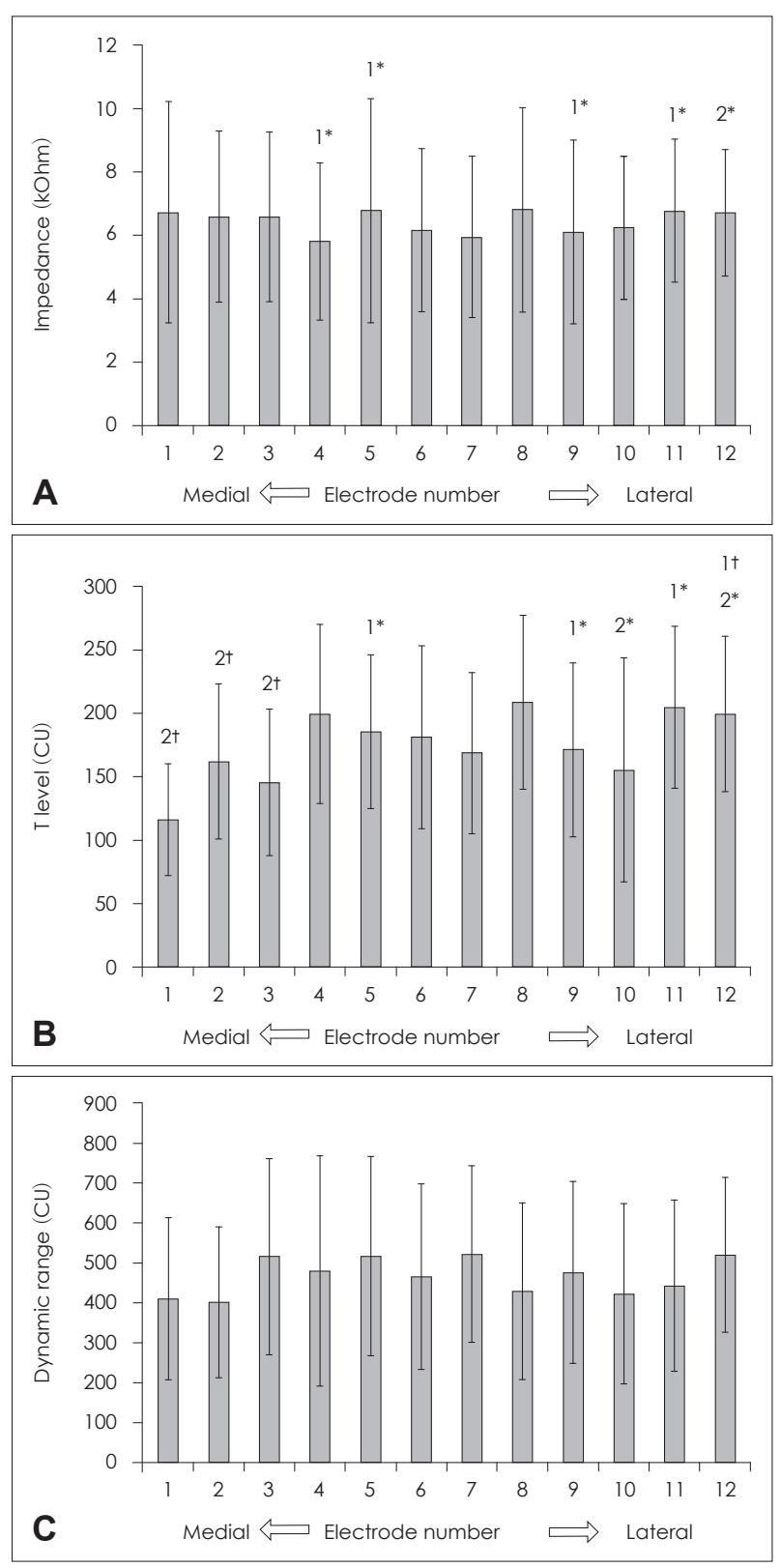

Fig. 1. Psycho-electrical parameters of each electrode. Impedance (A), T level (B), and Dynamic range (C). *number of patients in whom the corresponding electrode shows high impedance, †number of patients in whom the corresponding electrode shows a non-auditory response. CU: current unit, T level: threshold level. 
in 10 patients (seven congenital deaf and three postlingual deaf). The threshold for high frequency sound ( $2 \mathrm{k}, 56.0 \pm$ $15.4 \mathrm{~dB} ; 4 \mathrm{k}, 71.5 \pm 31.3 \mathrm{~dB} ; 6 \mathrm{k}, 70.5 \pm 32.44 \mathrm{~dB}$ ) was elevated and more variable than that for low frequency sound $(250 \mathrm{~Hz}$, $51.5 \pm 12.7 \mathrm{~dB} ; 500 \mathrm{~Hz}, 56.0 \pm 15.4 \mathrm{~dB} ; 1 \mathrm{k}, 57.2 \pm 18.2 \mathrm{~dB}$ ) (Fig. 2). According to the Ling 6 test, all 11 tested patients (eight congenital deaf and three postlingual deaf) detect the /Ah/ sound, and more than eight patients detected other sounds. However, identification of the sounds was more difficult for the patients. Two to four patients identified the /M/, /Oo/, Ee/, and $/ \mathrm{Ah} /$ sound. None could identify the relatively high pitch sounds /Sh/ and /S/ (Fig. 3).

\section{Pitch placing relationship}

Fig. 4 showed the result of pitch ranking in six patients (three congenital deaf and three postlingual deaf) who could respond consistently to the question of comparing the pitch of each electrode. Each patient showed a different pitch-placing pattern.

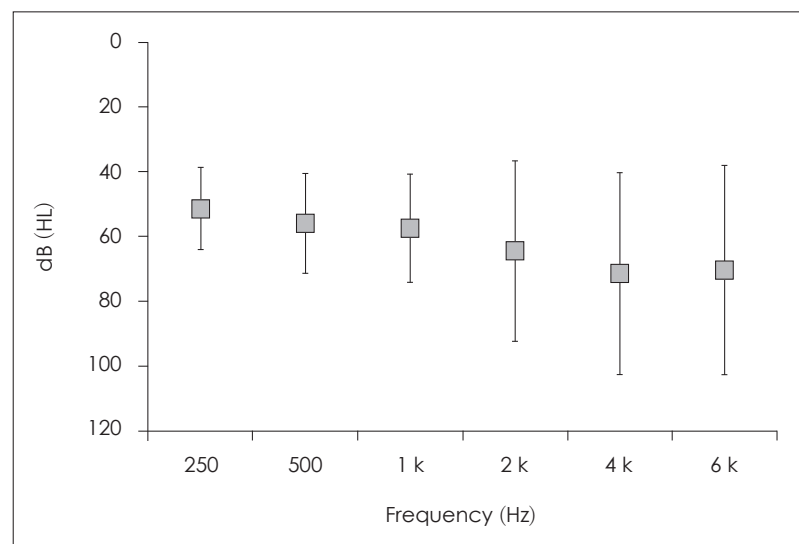

Fig. 2. Pure-tone threshold in sound field stimulation. The threshold is higher and variable among patients in the high frequency area.
In two patients (\#11 and \#12), the deeply inserted electrodes represented high pitch sound, and the superficial electrodes represented low pitch sound. By contrast, two other patients (\#15 and \#16) showed a reverse pattern. In the remaining two patients, the high pitch sound was detected in the center (\#14) or peripheral electrode (\#3).

Next, in these six patients, we compared the T level and dynamic ranges among the electrodes representing the three highest pitches and those representing the three lowest pitches (Fig. 5). The T level in high-pitch-perceiving electrodes of 234士 27 current units was higher than that of in the low-pitch-perceiving electrodes of $201 \pm 22$ current units. The dynamic

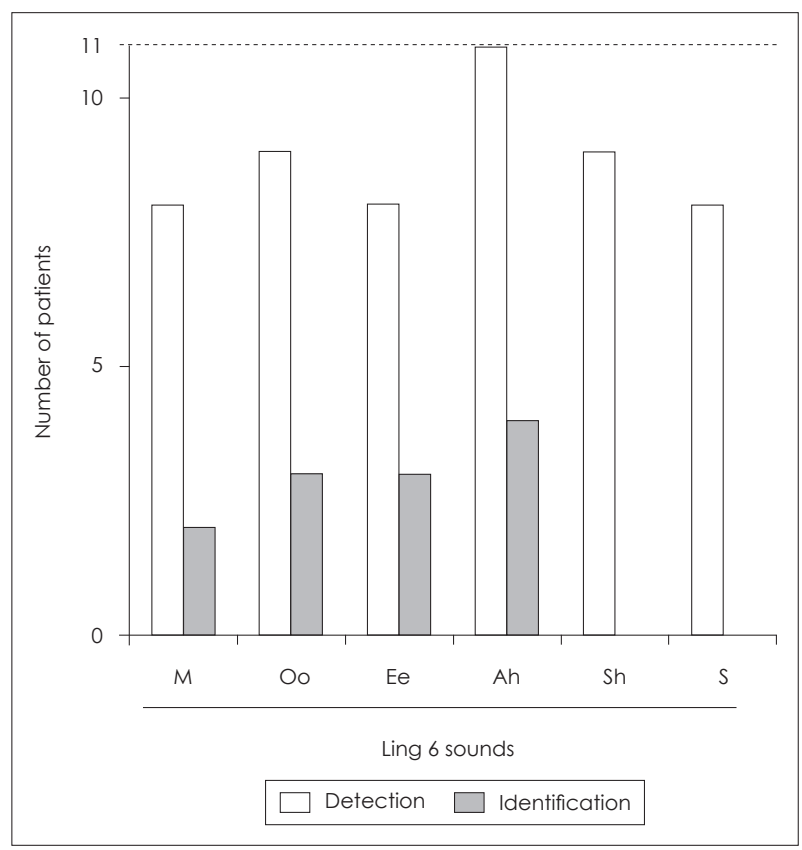

Fig. 3. Ling 6 sound detection-identification test. Most patients can detect all Ling 6 sounds but could not identify the /Sh/ and /s/ sounds.

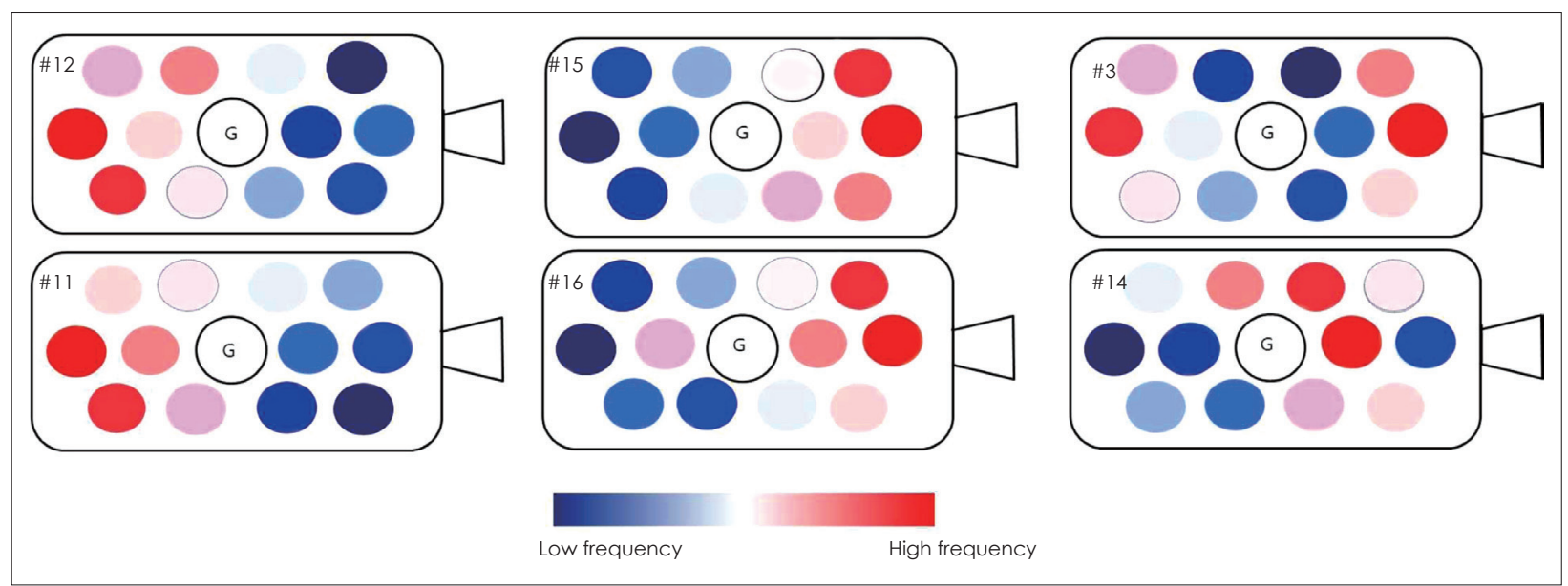

Fig. 4. Pitch-placing relationship in six patients. Electrodes perceiving high pitch sound are different in each patient. G: ground electrode. 

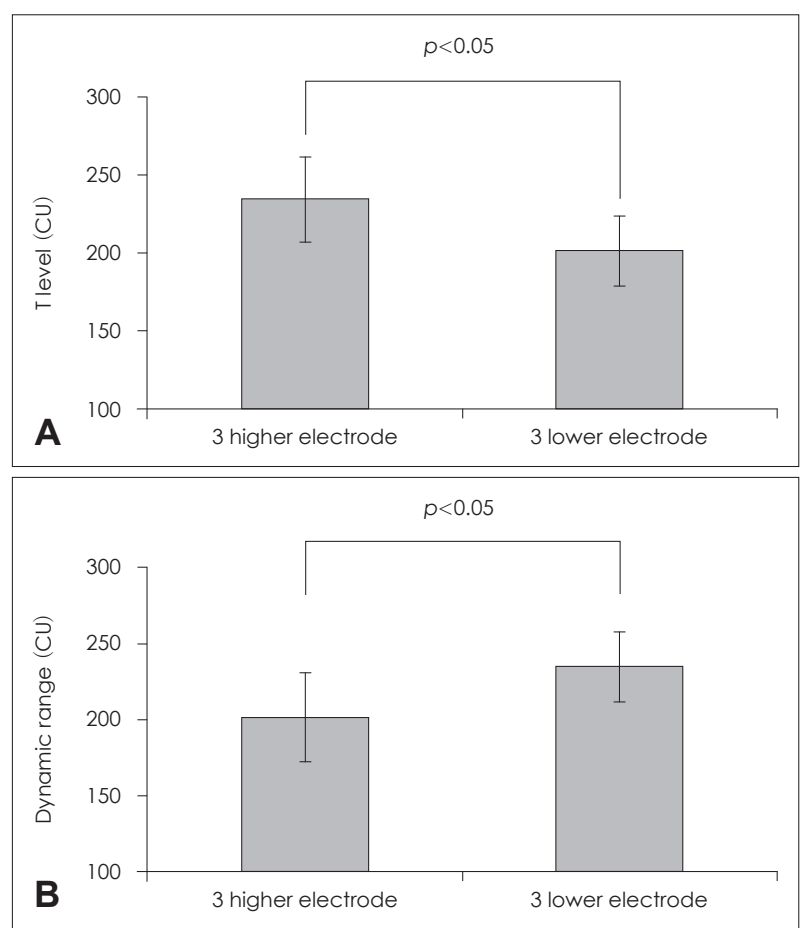

Fig. 5. Comparison of the T level (A) and dynamic range (B) among three high-pitch-perceiving and three low-pitch-perceiving electrodes. High-pitch-perceiving electrodes show an elevated T level and narrower dynamic range. CU: current unit, T level: threshold level.

range of the high-pitch-perceiving electrodes was narrower with $201 \pm 22.4$ current units than that of the low-pitch-perceiving electrodes with $234 \pm 27$ current units.

\section{Discussion}

Although ABI uses almost the same technology as CI, the average performance with $\mathrm{ABI}$ is not as good as that with $\mathrm{CI}$, and a large variation exists regarding the results with $\mathrm{ABI}$ among patients. Our results indicate that patients using ABI have difficulty in identifying high pitch sound such as /s/ and /sh/ sounds, and the pure-tone threshold for high frequency sound was elevated. Furthermore, the electrode representing high pitch sound has a narrow dynamic range and elevated threshold. One main reason for poor perception in high pitch sound seems to be the different tonotopy of the cochlear nucleus from that of the cochlea. The superficial layer represents low frequency sound, and the deep layer represents higher frequency sound in the cochlear nucleus. ${ }^{15)}$ Consequently, the surface electrode may have problems in the stimulation of high frequency sound. Another possible reason for the problem in high pitch sound involves the interface between the electrode and cochlear nucleus. However, our data showed that the im- pedance, T level, and dynamic range were not different among the electrodes. Therefore, more suitable stimulators other than surface type electrodes need to be developed to improve performance for high frequency sound. Although the animal study showed the greater tonotopic selectivity of penetrating type electrode and the NF-2 patients who received ABI with a penetrating type electrode heard sound more similar to pure tones with surface electrodes, the clinical trial failed to show improved speech understanding with penetrating electrodes. ${ }^{17)}$ Furthermore, more than $75 \%$ of electrodes could not provide auditory stimulation, and patients using penetrating electrodes reported significant side effects, including non-auditory stimulation (e.g., trigeminal nerve stimulation). If a more sophisticated penetrating electrode for improving pitch perception is developed, it could be of use in non-tumor patients because the poor performance with penetrating type electrodes in NF-2 patients might come from the destructive neural component of the tumor in this group of patients. Another solution for poor high pitch sound in patients with $\mathrm{ABI}$ is bimodal hearing. According to our preliminary data, CI in the opposite ear helps with high pitch perception in some patients using ABI.

Another problem for speech understanding in patients with $\mathrm{ABI}$ is the difficulty in pitch-ranked stimulation. According to a previous report, ${ }^{3)}$ the most frequent pattern in NF-2 patients was high frequency detection in the medial portion of electrodes. In contrast, Vincent, et al. ${ }^{18)}$ reported that most patients perceive high frequencies at the ventral portion of a stimulated brainstem. We found that we could not predict which electrode transmits the high frequency sound and which transmits the low frequency sound. The pitch ranking result is completely different among the patients. Therefore, in children, we cannot effectively map in whom pitch ranking is impossible. These problems may lead to poor speech understanding in children with ABI. Comparing speech perception in users with randomly assigned electrode to ABI users with the electrodes assigned to pitch ranking channels showed much improved speech perception. ${ }^{19,20)}$ Therefore, a more sophisticated mapping technique needs to be developed, particularly for children. In the future, functional imaging can help frequency-specific mapping in these circumstances.

\section{Acknowledgments}

This study was supported by a grant of the Korea Health technology R\&D Project, Ministry of Health \& Welfare, Republic of Korea (A102065).

\section{REFERENCES}

1) Lesinski-Schiedat A, Frohne C, Illg A, Rost U, Matthies C, Battmer 
$\mathrm{RD}$, et al. Auditory brainstem implant in auditory rehabilitation of patients with neurofibromatosis type 2: Hannover programme. J Laryngol Otol Suppl 2000;(27):15-7.

2) Eisenberg LS, Maltan AA, Portillo F, Mobley JP, House WF. Electrical stimulation of the auditory brain stem structure in deafened adults. J Rehabil Res Dev 1987;24(3):9-22.

3) Otto SR, Brackmann DE, Hitselberger WE, Shannon RV, Kuchta J. Multichannel auditory brainstem implant: update on performance in 61 patients. J Neurosurg 2002;96(6):1063-71.

4) Schwartz MS, Otto SR, Shannon RV, Hitselberger WE, Brackmann DE. Auditory brainstem implants. Neurotherapeutics 2008;5(1): 128-36.

5) Lenarz M, Matthies C, Lesinski-Schiedat A, Frohne C, Rost U, Illg A, et al. Auditory brainstem implant part II: subjective assessment of functional outcome. Otol Neurotol 2002;23(5):694-7.

6) Ebinger K, Otto S, Arcaroli J, Staller S, Arndt P. Multichannel auditory brainstem implant: US clinical trial results. J Laryngol Otol Suppl 2000;(27):50-3.

7) Maini S, Cohen MA, Hollow R, Briggs R. Update on long-term results with auditory brainstem implants in NF2 patients. Cochlear Implants Int 2009;10 Suppl 1:33-7.

8) Colletti V, Fiorino F, Sacchetto L, Miorelli V, Carner M. Hearing habilitation with auditory brainstem implantation in two children with cochlear nerve aplasia. Int J Pediatr Otorhinolaryngol 2001;60(2): 99-111.

9) Choi JY, Song MH, Jeon JH, Lee WS, Chang JW. Early surgical results of auditory brainstem implantation in nontumor patients. Laryngoscope 2011;121(12):2610-8.

10) Grayeli AB, Bouccara D, Kalamarides M, Ambert-Dahan E, Coudert C, Cyna-Gorse F, et al. Auditory brainstem implant in bilateral and completely ossified cochleae. Otol Neurotol 2003;24(1):79-82.

11) Sanna M, Khrais T, Guida M, Falcioni M. Auditory brainstem implant in a child with severely ossified cochlea. Laryngoscope 2006;116(9): 1700-3.

12) Sennaroglu L, Ziyal I, Atas A, Sennaroglu G, Yucel E, Sevinc S, et al. Preliminary results of auditory brainstem implantation in prelingually deaf children with inner ear malformations including severe stenosis of the cochlear aperture and aplasia of the cochlear nerve. Otol Neurotol 2009;30(6):708-15.

13) Colletti V, Carner M, Miorelli V, Guida M, Colletti L, Fiorino F. Auditory brainstem implant (ABI): new frontiers in adults and children. Otolaryngol Head Neck Surg 2005;133(1):126-38.

14) Sennaroglu L, Colletti V, Manrique M, Laszig R, Offeciers E, Saeed S, et al. Auditory brainstem implantation in children and non-neurofibromatosis type 2 patients: a consensus statement. Otol Neurotol 2011;32(2):187-91.

15) Moore JK. The human auditory brain stem: a comparative view. Hear Res 1987;29(1):1-32.

16) Ling D. Speech and the hearing-impaired child: theory and practice. 2nd ed. Washington, DC: Alexander Graham Bell Association for the Deaf and Hard of Hearing;2002.

17) Otto SR, Shannon RV, Wilkinson EP, Hitselberger WE, McCreery DB, Moore JK, et al. Audiologic outcomes with the penetrating electrode auditory brainstem implant. Otol Neurotol 2008;29(8):1147-54.

18) Vincent C, Zini C, Gandolfi A, Triglia JM, Pellet W, Truy E, et al. Results of the MXM Digisonic auditory brainstem implant clinical trials in Europe. Otol Neurotol 2002;23(1):56-60.

19) Otto $S$, Staller $S$. Multichannel auditory brain stem implant: case studies comparing fitting strategies and results. Ann Otol Rhinol Laryngol Suppl 1995;166:36-9.

20) Kuchta J, Otto SR, Shannon RV, Hitselberger WE, Brackmann DE. The multichannel auditory brainstem implant: how many electrodes make sense? J Neurosurg 2004;100(1):16-23. 